\title{
Emergency treatment of complicated colorectal cancer
}

This article was published in the following Dove Press journal: Cancer Management and Research

\author{
Giovanni Domenico Tebala' \\ Andrea Natili,2 \\ Antonio Gallucci' \\ Gioia Brachini² \\ Abdul Qayyum Khan' \\ Domenico Tebala ${ }^{3}$ \\ Andrea Mingoli ${ }^{2}$ \\ 'Colorectal Team, Noble's Hospital, \\ Strang, Douglas, Isle of Man, UK; \\ 2Emergency Surgery Unit, "P.Valdoni" \\ Department of Surgery, "Umberto \\ I" University Hospital, Rome, Italy; \\ ${ }^{3}$ National Institute of Statistics \\ (ISTAT), Catanzaro, Italy
}

Correspondence: Giovanni Domenico

Tebala

Colorectal Team, Noble's Hospital,

Strang, Douglas, Isle of Man IM4 4RJ, UK

Tel +44 I624650207

Email giovanni.tebala@nhs.net
Aim: To find evidence to suggest the best approach in patients admitted as an emergency for complicated colorectal cancer.

Methods: The medical records of 131 patients admitted as an emergency with an obstructing, perforated, or bleeding colorectal cancer to Noble's Hospital, Isle of Man, and the Umberto I University Hospital, Rome, were retrospectively evaluated. Patients were divided in 3 groups on the basis of the emergency treatment they received, namely 1) immediate resection, 2) damage control procedure and elective or semielective resection, and 3) no radical treatment. Demographic variables, clinical data, and treatment data were considered, and formed the basis for the comparison of groups. Primary endpoints were 90-day mortality and morbidity. Secondary endpoints were length of stay, number of lymph nodes analyzed, rate of radical R0 resections, and the number of patients who had chemoradiotherapy.

Results: Forty-two patients did not have any radical treatment because the cancer was too advanced or they were too ill to tolerate an operation, 78 patients had immediate resection and 11 had damage control followed by elective resection. There was no statistically significant difference between immediate resections and 2-stage treatment in 90-day mortality and morbidity (mortality: $15.4 \%$ vs $0 \%$; morbidity: $26.9 \%$ vs $27.3 \%$ ), number of nodes retrieved (16.6 \pm 9.4 vs $14.9 \pm 5.7$ ), and rate of R0 resections ( $84.6 \%$ vs $90.9 \%)$, but mortality was slightly higher in patients who underwent immediate resection. The patients who underwent staged treatment had a higher possibility of receiving a laparoscopic resection (11.5\% vs $36.4 \%)$.

Conclusion: The present study failed to demonstrate a clear superiority of one treatment with respect to the other, even if there is an interesting trend favoring staged resection.

Keywords: colorectal cancer, colorectal surgery, obstructing colorectal cancer, perforated colorectal cancer, emergency surgery

\section{Introduction}

Colorectal cancer (CRC) is the third most frequent malignant disease worldwide, with an incidence of more than a million new cases per year. ${ }^{1}$ In the UK and in Italy, $\mathrm{CRC}$ incidence is about 70 new cases/100,000/yr. ${ }^{2,3} \mathrm{~A}$ significant proportion of these patients (14\%-33\%) present as an emergency with bowel obstruction, perforation, or bleeding. ${ }^{4,5}$ Unfortunately, these cancers are usually more aggressive and have a worse prognosis than those treated electively. ${ }^{6}$

Despite the many attempts at standardization, the best treatment for CRC presenting as an emergency is still a matter for debate. ${ }^{7-9}$ Furthermore, different local arrangements make it difficult to find a homogeneous approach. In the UK, all cases of CRC must be managed by a Colorectal Multidisciplinary Team, ${ }^{10}$ where surgeons 
must be specifically trained and experienced in colorectal surgery. While this is feasible in elective cases, a colorectal surgeon may not be immediately available if the patient presents out of hours. In these cases, the emergency must be managed by the on-call surgeon and the patient must be transferred to the relevant team/hospital as soon as possible. However, Italy does not yet have this level of subspecialization, and CRCs are usually managed by general surgeons, both as emergency or elective cases. The classic approach has been to treat the cancer and its complication in one go with a resection in emergency. A new approach has recently emerged, in particular in the UK, due to the above reported concerns regarding the specific qualification and training of the emergency surgeons, deriving its basic concepts from trauma surgery. The philosophy of "damage control," initially proposed for trauma patients, has been extended to nontrauma conditions. ${ }^{11}$ In this approach, the surgical complication can be treated in the emergency setting with minimal and targeted procedures aimed at controlling the acute condition (obstruction, perforation, or bleeding) while the patient is stabilized, in order to delay the definitive treatment of the CRC until he or she can be transferred to the care of the specialized team. ${ }^{10}$

This retrospective study has been conducted to provide further evidence to support the choice of the best treatment for $\mathrm{CRC}$, namely immediate resection vs elective resection.

\section{Methods}

The medical records of all consecutive patients with CRC admitted as emergency from March 2013 to January 2017 under the care of the Colorectal Team of Noble's Hospital, Isle of Man (British Isles), and the Emergency Surgery Unit of the Umberto I University Hospital, Rome (Italy), have been retrospectively analyzed. The Noble's is a 314-bed teaching hospital serving about 90,000 citizens of the Isle of Man. The Isle of Man is located at the middle of the Irish Sea, about 60 miles from tertiary centers in mainland UK. The Colorectal Unit deals with about 80 new CRCs per year, both as elective and emergent cases. Umberto I is a 1,200-bed tertiary university hospital situated at the center of Rome; its Emergency Surgery Department is one of the busiest of the 20 emergency departments (EDs) in the capital city.

The patients' data regarding the treatment of their CRCs have been collected into an electronic database created with MS Excel for Mac v14.7.2 (Microsoft, Redmond, WA, USA), and each single variable was checked for typos and missing data. Variables with missing data $>10 \%$ were discarded. Afterward, data were imported and analyzed with IBM SPSS for Mac v.20.0.0. Distribution of continuous variables was checked.

The variables considered in the study were demographics (gender, age), clinical data (time between symptoms onset and admission, time between admission and first treatment, American Society of Anesthesiologists (ASA) score, type of emergency presentation), and treatment data (which emergency treatment, ostomy, laparoscopic vs open approach, eventual neoadjuvant or adjuvant treatment).

Primary endpoints were 90-day mortality and morbidity (Clavien >2). ${ }^{12}$ Secondary endpoints were length of stay, number of lymph nodes analyzed, rate of radical $\mathrm{R} 0$ resections, and the number of patients who had chemoradiotherapy.

The cancers have been staged with the usual systems (TNM and Dukes), but other parameters have also been considered, such as the number of positive nodes, lymph node ratio (positive nodes/total nodes), lymph-vascular infiltration, and the status of the circumferential resection margin.

Ordinal or nominal variables have been compared with Pearson's $\chi^{2}$ test. Frequencies are presented as number of cases and percentage. Continuous variables have been compared with the independent samples Student's $t$-test if the variable had a normal (Gaussian) distribution or with the Mann-Whitney $U$-test if the variable was not distributed normally. These variables are presented as mean \pm standard deviation and/or median and range.

The correlation between 2 or more continuous variables has been tested with linear regression analysis, whereas correlation between 2 or more nominal or ordinal variables has been tested with logistic regression analysis. Multiple logistic regression has been used to check for independent variables. All the analyzed variables have been considered in the multivariate analysis, irrespective of their significance at univariate analysis.

Values of $p<0.05$ (2-tailed test) have been considered significant, but borderline statistical significance has been discussed as well, as it may denote an important "trend" which did not reach statistical significance probably due to the size of the sample.

An initial evaluation has been done on the whole series, mostly to compare the data of the 2 participating units and establish if there was any difference due to national guidelines or local policies or attitude.

Subsequent elaboration has been carried out only on the series of patients who underwent radical treatment. Two groups have been compared: 1) patients who had emergency resection; and 2) patients treated with elective resection after initial stabilization and damage control procedure. 
The statistical methods of this study were reviewed by one of the authors (DT), who is a statistician at the Italian National Institute of Statistics.

The retrospective nature of this study made formal ethical approval unnecessary. However, the Ethical Committees of both the Noble's Hospital and the Umberto I Hospital have been informed, and they both considered ethical approval and patient consent were not necessary on the following bases: 1) data were completely anonymized, 2) data were collected as part of the normal treatment for those patients and were subsequently analyzed within an audit aimed at improving our quality of care, 3) patients were treated according to national and international guidelines (discussed below), and 4) no experimental or new treatments/protocols are included in this report. Written approval was obtained by the Audit Committee of the Noble's Hospital. Patients' data confidentiality was not breached as all data were collected and analyzed in an anonymized manner. All patients gave full informed consent to the treatment, either resection or nonoperative management.

This report has been written following the PROCESS guidelines. ${ }^{13}$

\section{Results}

A total of 131 medical records were examined, 71 from Noble's Hospital and 60 from the Umberto I University Hospital. Due to local restrictions, follow-up data and other clinical variables (amount of fluids given, transfusions, medications) were not available.

Results are reported in Tables 1-7.

The 2 initial groups were matched for gender distribution, age, and type of presentation. Manx patients had a higher rate of metastatic cancers $(41.4 \%$ vs $25.9 \%, p=0.065)$ (Table 1 ).

Forty-two patients $(32.1 \%)$ did not have a radical treatment. Thirteen out of these 42 patients had only medical palliative symptomatic treatment, whereas 29 underwent an invasive procedure. However, 5 patients had only an abdominal exploration (laparoscopic or open) with no active procedure. Twenty-four patients $(57.1 \%$ of the nonresectable patients) had some form of diversion (Table 2).

The majority of patients $(61.8 \%)$ had the first treatment within 24 hours from admission. This rate was higher in the Italian group ( $78.3 \%$ vs $47.9 \%, p=0.001)$.

Only 4 patients had colonic stenting as emergency treatment, so this parameter was not evaluated further.

The majority of patients had their first treatment by open surgery, but more than one-quarter of Manx patients had an emergency laparoscopy as first treatment. Forty-two percent of patients had a stoma as initial treatment (or part of it) (Table 2).

Females and patients with a high ASA score were more likely to receive an emergency resection. Clearly, perforated cancers were preferably resected in emergency, even if some patients with perforated colon cancer did not have any radical treatment due to too advanced cancer or too poor general conditions. The majority of patients with left colon cancers underwent resection on emergency, while about one-third of patients with rectal cancers had a 2-step procedure. A surprisingly high number of patients with right colon or rectal cancer did not have any radical treatment (Table 3 ).

Manx patients were more likely to receive neoadjuvant chemoradiotherapy or palliative chemotherapy. Young patients were more likely to receive chemo- or chemoradiotherapy. While the rate of patients not receiving any form of chemoradiotherapy was similar with respect to anatomical location of the tumor, neoadjuvant chemoradiotherapy was performed only in rectal cancer patients, whereas adjuvant chemotherapy was more frequent in left colon cancers and palliative chemotherapy in right colon cancers. The patients who had 2-step treatment and those who had laparoscopic resection were more likely to receive chemo- and/or radiotherapy (Tables 4 and 5).

Further analysis was performed on the group of 89 patients who had radical treatment, that is 52 patients $(86.7 \%)$ of the Italian group and 37 (52.1\%) of the Manx group. Seventy-eight patients had immediate resection, whereas 11 had damage control and subsequent elective resection. Immediate resection was performed by laparoscopy in $11.5 \%$ of cases ( 9 patients), whereas delayed resection was completed by laparoscopy in $36.4 \%$ of cases ( 4 patients) ( $p=0.029$ ). All patients were operated on by consultants. All patients with staged treatment were operated on by subspecialist colorectal surgeons after discussion at a colorectal multidisciplinary team meeting.

Table 6 reports the results of univariate analysis with respect to the study endpoints.

In multivariate analysis (Table 7), mortality and morbidity were significantly directly correlated to the ASA score and Dukes stage. Furthermore, the laparoscopic technique was an independent protective factor for morbidity. Longer stays were related to late admission and delayed first treatment. The only independent factor increasing the risk of having a stoma was distal location of the cancer. Chemo- and/or radiotherapy has been offered more frequently to young patients. The number of nodes analyzed was independently related to the ASA score and location of the cancer. The ASA score was 
Table I Demographics and basic clinical data

\begin{tabular}{|c|c|c|c|c|}
\hline & Total & Umberto I University Hospital & Noble's Hospital & $p$-value \\
\hline Number of cases & $|3|$ & $60(45.8 \%)$ & 7I (54.2\%) & \\
\hline Gender & & & & 0.495 \\
\hline M & $70(53.4 \%)$ & $34(56.7 \%)$ & $36(50.7 \%)$ & \\
\hline $\mathrm{F}$ & $6 \mathrm{I}(46.6 \%)$ & $26(43.3 \%)$ & $35(49.3 \%)$ & \\
\hline \multirow[t]{2}{*}{ Age (years) ${ }^{\mathrm{a}}$} & $73.5 \pm 12.6$ & $73.3 \pm 11.7$ & $73.7 \pm 13.3$ & 0.862 \\
\hline & $74(35-97)$ & $73.5(43-94)$ & $74(35-97)$ & \\
\hline Presentation & & & & 0.480 \\
\hline Obstruction & $108(82.4 \%)$ & 47 (78.3\%) & $6 \mathrm{I}(85.9 \%)$ & \\
\hline Perforation & 15 (II.5\%) & $8(13.3 \%)$ & $7(9.9 \%)$ & \\
\hline Bleeding & $8(6.1 \%)$ & $5(8.3 \%)$ & $3(4.2 \%)$ & \\
\hline \multirow[t]{2}{*}{ Symptom onset to admission (days) ${ }^{\mathrm{a}}$} & $19.3 \pm 61.6$ & $19.9 \pm 57.8$ & $18.7 \pm 65.1$ & 0.003 \\
\hline & $2(0-488)$ & $4.5(0-375)$ & I (0-488) & \\
\hline \multirow[t]{2}{*}{ Admission to first treatment (days) ${ }^{\mathrm{a}}$} & $4.1 \pm 11.3$ & $3.0 \pm 13.0$ & $5.2 \pm 9.3$ & 0.006 \\
\hline & $0(0-99)$ & $0(0-99)$ & I (0-37) & \\
\hline ASA & & & & 0.015 \\
\hline 1 & $8(6.1 \%)$ & 0 & 8 (II.3\%) & \\
\hline 2 & 43 (32.8\%) & 18 (30.0\%) & $25(35.2 \%)$ & \\
\hline 3 & $55(42.0 \%)$ & 32 (53.3\%) & $23(32.4 \%)$ & \\
\hline 4 & $24(18.3 \%)$ & $9(15.0 \%)$ & $15(21.1 \%)$ & \\
\hline 5 & I (0.8\%) & I (I.7\%) & 0 & \\
\hline $\mathrm{T}$ & & & & 0.395 \\
\hline 2 & $2(1.6 \%)$ & 0 & $2(2.9 \%)$ & \\
\hline 3 & 59 (46.1\%) & $26(44.8 \%)$ & $33(47.1 \%)$ & \\
\hline 4 & $67(52.3 \%)$ & 32 (55.2\%) & 35 (50.0\%) & \\
\hline (Missing) & 3 & 2 & 1 & \\
\hline $\mathrm{N}$ & & & & 0.343 \\
\hline 0 & $50(39.4 \%)$ & $26(45.6 \%)$ & $24(34.2 \%)$ & \\
\hline 1 & $34(26.8 \%)$ & $16(28.1 \%)$ & 18 (25.7\%) & \\
\hline 2 & $42(33.1 \%)$ & $15(26.3 \%)$ & $27(38.6 \%)$ & \\
\hline (Missing) & 5 & 3 & 2 & \\
\hline$M$ & & & & 0.065 \\
\hline 0 & $84(65.6 \%)$ & 43 (74.1\%) & $4 \mathrm{I}(58.6 \%)$ & \\
\hline 1 & 44 (34.4\%) & 15 (25.9\%) & 29 (4I.4\%) & \\
\hline (Missing) & 3 & 2 & 1 & \\
\hline Location & & & & 0.020 \\
\hline Right colon & $54(41.2 \%)$ & 17 (28.3\%) & $37(52.1 \%)$ & \\
\hline Left colon & 50 (38.2\%) & 27 (45.0\%) & $23(32.4 \%)$ & \\
\hline Rectum & 27 (20.6\%) & $16(26.7 \%)$ & II (I5.5\%) & \\
\hline Emergency treatment & & & & 0.000 \\
\hline Immediate resection & 78 (59.5\%) & 48 (80.0\%) & $30(42.3 \%)$ & \\
\hline DCS & II (8.4\%) & $4(6.7 \%)$ & 7 (9.9\%) & \\
\hline Palliative treatment & $42(32.1 \%)$ & $8(13.3 \%)$ & $34(47.9 \%)$ & \\
\hline
\end{tabular}

Notes: National groups comparison ( ${ }^{a}$ mean \pm standard deviation, median and range). Significant $p$-values are reported in bold.

Abbreviations: ASA, American Society of Anesthesiologists; DCS, damage control surgery.

also independently related to the rate of adequate clearance, along with Dukes' stage. Interestingly, also on multivariate analysis, infiltration of the surgical margin was more frequent in patients operated on by open surgery and in those with delayed emergency treatment at first admission.

\section{Discussion}

Although the elective approach to CRCs has already been defined and national guidelines and local protocols have been released and widely followed, the treatment of CRC present- ing as emergency - obstruction, perforation, or significant bleeding - has yet to be standardized and often the choice is left with the on-duty/on-call surgeon. UK guidelines suggest that every CRC - elective or emergency - must be managed by a consultant colorectal surgeon who is a core member of a multidisciplinary team. ${ }^{10}$ Clearly, this may not be possible if the patient is admitted off-hours, when the colorectal surgeon may not be on-call. In this case, the patient should be transferred under the care of the relevant team as soon as possible. ${ }^{10}$ Nonetheless, it is not completely clear if treatable 
Table 2 Emergency treatment

\begin{tabular}{|c|c|c|c|}
\hline & Total & Umberto I University Hospital & Noble's Hospital \\
\hline Total & 131 & $60(45.8 \%)$ & $7 \mathrm{l}(54.2 \%)$ \\
\hline Radical resection & 89 & 52 (58.4\%) (86.7\% within group) & 37 (4I.6\%) (52.1\% within group) \\
\hline Immediate resection & 78 & 48 (61.5\%) & $30(38.5 \%)$ \\
\hline Right colectomy & $25(32.1 \%)$ & $9(18.8 \%)$ & $16(53.3 \%)$ \\
\hline Extended right colectomy & $8(10.3 \%)$ & $5(10.4 \%)$ & $3(10.0 \%)$ \\
\hline Left colectomy & $18(23.1 \%)$ & $15(31.3 \%)$ & $3(16.7 \%)$ \\
\hline Extended left colectomy & I (I.3\%) & 0 & I (3.3\%) \\
\hline Hartmann's & $10(12.8 \%)$ & 7 (14.6\%) & $3(10.0 \%)$ \\
\hline Sigmoid colectomy & $2(6.7 \%)$ & 0 & $2(2.6 \%)$ \\
\hline Anterior resection & $\mathrm{I}(\mathrm{I} .3 \%)$ & $\mathrm{I}(2.1 \%)$ & 0 \\
\hline Subtotal colectomy & $3(3.8 \%)$ & $2(4.2 \%)$ & I (3.3\%) \\
\hline \multirow[t]{2}{*}{ Total colectomy } & $10(12.8 \%)$ & $9(18.8 \%)$ & I (3.3\%) \\
\hline & & $p=0.012$ & \\
\hline Damage control & II & $4(36.4 \%)$ & 7 (63.6\%) \\
\hline Loop colostomy & $9(81.8 \%)$ & $2(50.0 \%)$ & $7(100 \%)$ \\
\hline \multirow[t]{2}{*}{ Stent } & $2(18.2 \%)$ & $2(50.0 \%)$ & 0 \\
\hline & & $p=0.039$ & \\
\hline Palliative treatment & 42 & $8(19.0 \%)$ & 34 (81.0\%) \\
\hline Terminal colostomy & I (2.4\%) & $\mathrm{I}(12.5 \%)$ & 0 \\
\hline Loop colostomy & 7 (16.7\%) & $2(25.0 \%)$ & $5(14.7 \%)$ \\
\hline Terminal ileostomy & $3(7.1 \%)$ & $3(8.8 \%)$ & 0 \\
\hline Loop ileostomy & $8(19.0 \%)$ & $2(25.0 \%)$ & $6(17.6 \%)$ \\
\hline Ileotransverse bypass & $3(7.1 \%)$ & 0 & $3(8.8 \%)$ \\
\hline Diagnostic laparoscopy & $2(4.8 \%)$ & 0 & $2(5.9 \%)$ \\
\hline Exploratory laparotomy & $3(7.1 \%)$ & I (I2.5\%) & $2(5.9 \%)$ \\
\hline Stent & $2(4.8 \%)$ & I (I2.5\%) & I (2.9\%) \\
\hline \multirow[t]{2}{*}{ Medical treatment } & $13(31.0 \%)$ & I (I2.5\%) & $12(35.3 \%)$ \\
\hline & & $p=0.305$ & \\
\hline Colostomy ${ }^{a}$ & $28(21.4 \%)$ & $12(20.0 \%)$ & $16(22.5 \%)$ \\
\hline lleostomy & 27 (20.6\%) & $16(26.7 \%)$ & II (I5.5\%) \\
\hline \multirow[t]{2}{*}{ No stoma } & $76(58.0 \%)$ & $32(53.3 \%)$ & $44(62.0 \%)$ \\
\hline & & $p=0.289$ & \\
\hline Laparotomy & 89 (67.9\%) & $5 \mathrm{I}(85.0 \%)$ & $38(53.5 \%)$ \\
\hline Laparoscopy & $23(17.6 \%)$ & $3(5.0 \%)$ & $20(28.2 \%)$ \\
\hline Conversion lap-open & $2(1.5 \%)$ & $2(3.3 \%)$ & 0 \\
\hline \multirow[t]{2}{*}{ No operation } & $17(13.0 \%)$ & $4(6.7 \%)$ & $13(18.3 \%)$ \\
\hline & & $p=0.000$ & \\
\hline Emergency surgery $<24 \mathrm{~h}$ & $8 \mathrm{l}(6 \mathrm{I} .8 \%)$ & 47 (78.3\%) & 34 (47.9\%) \\
\hline Delayed surgery $>24 \mathrm{~h}$ & 37 (28.2\%) & $12(20 \%)$ & 25 (35.2\%) \\
\hline \multirow[t]{2}{*}{ Medical treatment } & 13 (9.9\%) & I (I.7\%) & 12 (16.9\%) \\
\hline & & $p=0.001$ & \\
\hline
\end{tabular}

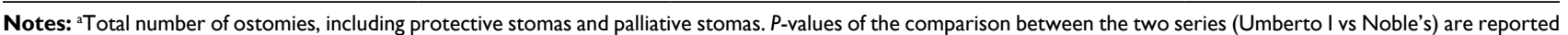
in bold.

patients should be resected in emergency by the on-call surgeons or just stabilized with a damage control procedure and then transferred to the colorectal surgeon for the definitive treatment. Clearly, there are situations where an emergency resection is mandatory, but more often the definitive treatment can be safely postponed, provided that the emergency complication is somehow controlled and the general condition of the patient is stabilized and possibly improved, following the same principles of damage control surgery for trauma. ${ }^{11}$ In obstructing CRC, damage-control surgery (DCS) entails resolving bowel obstruction with a diversion procedure (ileostomy, colostomy, internal bypass, stent). In a perforated CRC, DCS may overlap with definitive treatment if an emergency resection of the perforated bowel has to be performed, although in patients in poor general condition and without a generalized peritonitis it could be sensible to consider only percutaneous drainage and proximal diversion. Bleeding CRC can be treated at emergency with transfusions and/or embolization and/or bleeding control with laser.

Unfortunately, these patients still have a poor prognosis, and up to $20 \%$ of those operated on for acute obstruction due to CRC die within 1 month of the operation. ${ }^{14}$ Although 
Table 3 Distribution of the emergency treatments by factors

\begin{tabular}{|c|c|c|c|c|}
\hline & Immediate resection & Damage control & Palliative treatment & $p$-value \\
\hline Total & 78 (59.5\%) & II (8.4\%) & $42(32.1 \%)$ & \\
\hline Gender & & & & 0.031 \\
\hline M & $38(54.3 \%)$ & $10(14.3 \%)$ & $22(3 \mid .4 \%)$ & \\
\hline $\mathrm{F}$ & $40(65.6 \%)$ & $\mathrm{I}(\mathrm{I} .6 \%)$ & $20(32.8 \%)$ & \\
\hline ASA & & & & 0.057 \\
\hline I & I (I2.5\%) & $2(25.0 \%)$ & $5(62.5 \%)$ & \\
\hline 2 & $23(53.5 \%)$ & $5(11.6 \%)$ & $15(34.9 \%)$ & \\
\hline 3 & $36(65.5 \%)$ & $4(7.3 \%)$ & 15 (27.3\%) & \\
\hline 4 & $18(75.0 \%)$ & 0 & $6(25.0 \%)$ & \\
\hline 5 & 0 & 0 & I (100\%) & \\
\hline Presentation & & & & 0.043 \\
\hline Obstruction & $63(58.3 \%)$ & $9(8.3 \%)$ & $36(33.3 \%)$ & \\
\hline Perforation & $13(86.7 \%)$ & 0 & $2(13.3 \%)$ & \\
\hline Bleeding & $2(25.0 \%)$ & $2(25.0 \%)$ & $4(50.0 \%)$ & \\
\hline Location & & & & 0.000 \\
\hline Proximal colon & $32(59.3 \%)$ & 0 & $22(40.7 \%)$ & \\
\hline Distal colon & $38(76.0 \%)$ & $3(6.0 \%)$ & $9(18.0 \%)$ & \\
\hline Rectum & $8(29.6 \%)$ & $8(29.6 \%)$ & II (40.7\%) & \\
\hline
\end{tabular}

Note: Significant $p$-values are reported in bold.

Abbreviation: ASA, American Society of Anaesthesiologists.

Table 4 Chemotherapy/radiotherapy

\begin{tabular}{|c|c|c|c|c|c|}
\hline & $\begin{array}{l}\text { Neoadjuvant } \\
\text { radiochemotherapy }\end{array}$ & $\begin{array}{l}\text { Adjuvant } \\
\text { chemotherapy }\end{array}$ & $\begin{array}{l}\text { Palliative } \\
\text { chemotherapy }\end{array}$ & $\begin{array}{l}\text { No radiotherapy } \\
\text { or chemotherapy }\end{array}$ & $p$-value \\
\hline Total & $6(4.6 \%)$ & $42(32.1 \%)$ & $16(12.2 \%)$ & $67(51.1 \%)$ & \\
\hline Umberto I & $\mathrm{I}(\mathrm{I} .7 \%)$ & $23(38.3 \%)$ & $3(5.0 \%)$ & $33(55.0 \%)$ & 0.038 \\
\hline Noble's & $5(7.0 \%)$ & 19 (26.8\%) & $13(18.3 \%)$ & 34 (47.9\%) & \\
\hline$<70 y$ & $5(9.8 \%)$ & $2 \mid(4 I .2 \%)$ & $8(15.7 \%)$ & $17(33.3 \%)$ & 0.004 \\
\hline$\geq 70 y$ & I (I.3\%) & $21(26.3 \%)$ & $8(10.0 \%)$ & $50(62.5 \%)$ & \\
\hline ASA I & I (I2.5\%) & $2(25.0 \%)$ & I (12.5\%) & $4(50 \%)$ & 0.317 \\
\hline ASA 2 & $3(7.0 \%)$ & $14(32.6 \%)$ & $9(20.9 \%)$ & $17(39.5 \%)$ & \\
\hline ASA 3 & $2(3.6 \%)$ & 21 (38.2\%) & 5 (9.1\%) & 27 (49.1\%) & \\
\hline ASA 4 & 0 & 5 (20.8\%) & I (4.2\%) & I8 (75.0\%) & \\
\hline ASA 5 & 0 & 0 & 0 & I (100\%) & \\
\hline Proximal colon & 0 & 17 (31.5\%) & $10(18.5 \%)$ & 27 (50.0\%) & 0.000 \\
\hline Distal colon & 0 & $20(40.0 \%)$ & $4(8.0 \%)$ & $26(52.0 \%)$ & \\
\hline Rectum & $6(22.2 \%)$ & $5(18.5 \%)$ & $2(7.4 \%)$ & $14(51.9 \%)$ & \\
\hline Immediate resection & 0 & $39(50.0 \%)$ & 0 & 39 (50.0\%) & 0.000 \\
\hline DCS + resection & 5 (45.5\%) & $3(27.3 \%)$ & 0 & $3(27.3 \%)$ & \\
\hline Palliative treat & I (2.4\%) & 0 & $16(38.1 \%)$ & 25 (59.5\%) & \\
\hline Laparotomy & $3(2.5 \%)$ & 37 (3I.4\%) & $16(13.6 \%)$ & $62(52.5 \%)$ & 0.004 \\
\hline Laparoscopy & $3(23.1 \%)$ & $5(38.5 \%)$ & 0 & 5 (38.5\%) & \\
\hline
\end{tabular}

Note: Significant $p$-values are reported in bold.

Abbreviations: ASA, American Society of Anesthesiologists; DCS, damage control surgery; y, year.

this may partly reflect the more advanced staging of CRC patients presenting as emergency, there is evidence that the worse outcome may also be due to the fact that these patients are usually managed in emergency by nonspecialist general surgeons. ${ }^{15}$

In nonoperable patients, symptom control can be achieved with an operative procedure such as a proximal diversion or an internal bypass or - better still - a stent, but often the disease is so advanced or the patient is so ill that not even a palliative procedure can be considered. Almost half of the nonresectable patients in this series had such an advanced cancer that no palliative procedure was possible.

It is not clear if in advanced cancers a better palliation can be achieved with ileostomy or colostomy. The former is usually easier and quicker but may not be able to reduce the pressure in a distended colon if the ileocecal valve is continent. The latter can be preferable as it can guarantee a good diversion with fewer side effects than ileostomy, but it often requires a degree of mobilization. Self-expandable stents are currently a very good option for patients with acutely obstructing CRC, either 
Table 5 Elective resections after damage control

\begin{tabular}{|c|c|c|c|}
\hline & Total & $\begin{array}{l}\text { Umberto I } \\
\text { University } \\
\text { Hospital }\end{array}$ & $\begin{array}{l}\text { Noble's } \\
\text { Hospital }\end{array}$ \\
\hline Hartmann & $2(18.2 \%)$ & $2(50.0 \%)$ & 0 \\
\hline Left colectomy & $2(18.2 \%)$ & I (25.0\%) & I (I4.3\%) \\
\hline $\begin{array}{l}\text { Abdomino-perineal } \\
\text { resection }\end{array}$ & I (9.1\%) & 0 & I (9.1\%) \\
\hline Anterior resection & $3(27.3 \%)$ & I (25.0\%) & $2(27.3 \%)$ \\
\hline Exenteration & I (9.1\%) & 0 & I (9.1\%) \\
\hline Total proctocolectomy & I (9.1\%) & 0 & I (9.1\%) \\
\hline Extended right & I (9.1\%) & 0 & I (9.1\%) \\
\hline \multicolumn{4}{|l|}{ colectomy } \\
\hline & & \multicolumn{2}{|c|}{$p=0.428$} \\
\hline Colostomy & $3(27.3 \%)$ & $2(50.0 \%)$ & I (I4.3\%) \\
\hline Ileostomy & $4(36.4 \%)$ & 0 & $4(57.1 \%)$ \\
\hline Colostomy + urostomy & I (9.1\%) & 0 & I (I4.3\%) \\
\hline \multirow[t]{2}{*}{ No stomia } & $3(27.3 \%)$ & $2(50 \%)$ & I (I4.3\%) \\
\hline & & \multicolumn{2}{|c|}{$p=0.155$} \\
\hline Laparotomy & 7 (63.6\%) & $4(100 \%)$ & $3(42.9 \%)$ \\
\hline \multirow[t]{2}{*}{ Laparoscopy } & $4(36.4 \%)$ & 0 & $4(57.1 \%)$ \\
\hline & & \multicolumn{2}{|c|}{$p=0.058$} \\
\hline
\end{tabular}

Note: Significant $p$-values are reported in bold.

as a definitive palliative measure or as a bridge to surgery, ${ }^{16,17}$ but in the present series only a few patients had colonic stenting, and so this parameter has not been analyzed.

In patients with an operable disease, both available approaches (immediate or delayed resection after DCS) can be acceptable. ACPGBI 2007 guidelines ${ }^{16}$ suggest immediate resection and anastomosis for obstructing CRC, mostly on the basis of old studies. ${ }^{18}$ The recently published ACPGBI 2017 guidelines are less specific and suggest optimization of the patient in a high-dependency unit before considering emergency surgery or stenting. ${ }^{19}$ On the contrary, NCCN 2016 guidelines ${ }^{20}$ consider both emergency resection or elective resection after ileostomy or colostomy as viable options. Actually, while some studies failed to demonstrate any outcome difference between immediate or delayed resection, ${ }^{21}$ there is similarly good evidence claiming that a phased strategy is associated with lower mortality and morbidity. ${ }^{7} \mathrm{~A}$ recent study from Sweden showed that a 2-stage treatment is associated with lower morbidity and better nodal clearance in comparison to immediate resection. ${ }^{9}$ However, in this study the vast majority of emergency resections were carried out by noncolorectal surgeons, whereas subspecialized colorectal surgeons usually preferred a staged strategy. On the contrary, a recent study from Korea suggested that every patient with obstruction due to CRC must have an emergency subtotal colectomy, on the basis that staged operations are associated with higher mortality and morbidity and longer hospital stay in comparison to immediate resections. ${ }^{22}$
As regards the patients with acute abdomen due to a perforated CRC, they almost always need an emergency resection, bearing in mind that those cancers are normally quite advanced and their long-term prognosis is generally poor. ${ }^{23}$ An extended operation on these patients is associated with higher morbidity and mortality ${ }^{24}$ so sometimes it may be sensible to try a conservative approach. In our series, none of the patients with a perforation had a staged resection and most of them underwent immediate resection.

This study was planned to try to obtain some further scientific evidence that could potentially be useful in the decision-making process.

The total number of cases in this analysis is quite high, although fortunately the number of CRC cases admitted as emergencies is gradually decreasing in Western countries due to screening programs and general public awareness. The Isle of Man is a closed environment, so the number of patients recruited in this study can be considered an exact estimate of the real incidence of complicated CRCs (71 cases in 4 years in a population of 87,000 equates to an incidence of about 21 cases $/ 100,000 / \mathrm{yr}$ ) and matches the data of the UK national audit ${ }^{25}$ and the results published in the literature. ${ }^{6}$ On the contrary, it is almost impossible to estimate the real incidence of complicated CRC in Italy on the basis of only the series from Rome, due to local factors. In fact, the Umberto I Emergency Department is only 1 out of 20 EDs in Rome, and every one of them has a different workload. For some reason, the distribution of surgical emergencies is not uniform within the emergency network in the capital city of Rome. Moreover, also within the Umberto I University Hospital, a number of patients with complicated bowel cancer have not been treated by the emergency surgeons and have been transferred under other consultants within the same hospital or to other tertiary centers, so their data have not been retrieved. The Manx and Italian groups match very well for age, gender, TN staging of the tumor, and acute complication leading to admission, so the pooled analysis of the 2 groups can be considered methodologically correct.

However, some evident differences must be emphasized, probably due to local policies and attitudes. In fact, whereas Manx patients were admitted earlier than the Italian ones with respect to the onset of their symptoms, it appears that their emergency treatment was somehow delayed once they were admitted. In our opinion, this may reflect the particular geographic configuration of the Isle of Man, where the health care services can be easily and quickly accessed by any patient, as opposed to the relatively difficult emergency access to hospital and specialist review in Rome, but also to 
Table 6 Univariate analysis on resected patients (89 cases)

\begin{tabular}{|c|c|c|c|c|c|c|c|c|}
\hline & Mortality & Morbidity $^{\mathbf{a}}$ & LOS $^{b}$ & Ostomy & $\begin{array}{l}\text { Complementary } \\
\text { treatment }\end{array}$ & LN analyzed & $\begin{array}{l}\text { LN } \\
\text { adequate } \\
\text { clearance }\end{array}$ & RO \\
\hline Total & $12(13.5 \%)$ & $24(27.0 \%)$ & $\begin{array}{l}16.8 \pm 19.8 \\
10(1-122)\end{array}$ & $37(41.6 \%)$ & $47(52.8 \%)$ & $\begin{array}{l}16.4 \pm 9.1 \\
14.5(0-64)\end{array}$ & 65 (73.0\%) & 76 (85.4\%) \\
\hline \multicolumn{9}{|l|}{ Age (years) } \\
\hline$<70$ & $2(5.7 \%)$ & 7 (20.0\%) & $\begin{array}{l}14.4 \pm 13.4 \\
10(4-79)\end{array}$ & $13(37.1 \%)$ & 25 (71.4\%) & $\begin{array}{l}19.4 \pm 11.0 \\
17.5(5-64)\end{array}$ & 27 (77.1\%) & $28(80.0 \%)$ \\
\hline$\geq 70$ & $10(18.5 \%)$ & 17 (31.5\%) & $\begin{array}{l}18.0 \pm 20.8 \\
10.5 \\
(1-122)\end{array}$ & $24(44.4 \%)$ & $22(40.7 \%)$ & $\begin{array}{l}14.4 \pm 6.9 \\
13(0-33)\end{array}$ & 38 (70.4\%) & $48(88.9 \%)$ \\
\hline$p$ & 0.084 & 0.233 & $0.980^{c}$ & 0.495 & 0.005 & $0.030^{c}$ & 0.482 & 0.246 \\
\hline \multicolumn{9}{|l|}{ Presentation } \\
\hline Obstruction & $9(12.5 \%)$ & $17(23.6 \%)$ & $\begin{array}{l}15.4 \pm 17.5 \\
10(1-122)\end{array}$ & $26(36.1 \%)$ & 39 (54.2\%) & $\begin{array}{l}17.2 \pm 9.7 \\
15(0-64)\end{array}$ & $53(73.6 \%)$ & $63(87.5 \%)$ \\
\hline Perforatation & $2(15.4 \%)$ & $4(30.8 \%)$ & $\begin{array}{l}19.3 \pm 21.6 \\
10(1-79)\end{array}$ & 9 (69.2\%) & $6(46.2 \%)$ & $\begin{array}{l}12.7 \pm 3.9 \\
14(5-19)\end{array}$ & $10(76.9 \%)$ & 10 (76.9\%) \\
\hline Bleeding & I (25.0\%) & $3(75.0 \%)$ & $\begin{array}{l}29.3 \pm 18.8 \\
28(11-50)\end{array}$ & $2(50.0 \%)$ & $2(50.0 \%)$ & $\begin{array}{l}12.0 \pm 3.6 \\
11(9-16)\end{array}$ & $2(50.0 \%)$ & $3(75.0 \%)$ \\
\hline$p$ & 0.758 & 0.075 & $0.140^{c}$ & 0.078 & 0.862 & $0.204^{c}$ & 0.552 & 0.509 \\
\hline Onset to admission & $0.329^{d}$ & $0.35 I^{d}$ & $0.103^{d}$ & $0.553^{d}$ & $0.706^{\mathrm{d}}$ & $0.569^{d}$ & $0.290^{\mathrm{d}}$ & $0.125^{d}$ \\
\hline $\begin{array}{l}\text { Admission to } \\
\text { treatment }\end{array}$ & $0.549^{d}$ & $\begin{array}{l}\text { Coeff } 0.007 \\
0.079^{d}\end{array}$ & $\begin{array}{l}\text { Coeff } 0.986 \\
0.000^{d}\end{array}$ & $0.335^{d}$ & $0.665^{d}$ & $0.75 \mathrm{I}^{\mathrm{d}}$ & $0.173^{d}$ & $0.102^{\mathrm{d}}$ \\
\hline \multicolumn{9}{|l|}{ ASA } \\
\hline I & 0 & 0 & $\begin{array}{l}9.0 \pm 7.0 \\
6(4-17)\end{array}$ & $2(66.7 \%)$ & $3(100 \%)$ & $\begin{array}{l}45.5 \pm 26.2 \\
45.5(27-64)\end{array}$ & $3(100 \%)$ & 2 (66.7\%) \\
\hline 2 & $2(7.1 \%)$ & $5(17.9 \%)$ & $\begin{array}{l}15.9 \pm 14.2 \\
9(6-64)\end{array}$ & $10(35.7 \%)$ & 17 (60.7\%) & $\begin{array}{l}18.0 \pm 7.4 \\
\text { I5.5 (2-33) }\end{array}$ & $25(89.3 \%)$ & $23(82.1 \%)$ \\
\hline 3 & $2(5.0 \%)$ & 9 (22.5\%) & $\begin{array}{l}19.0 \pm 21.5 \\
11(1-122)\end{array}$ & $16(40.0 \%)$ & 22 (55.0\%) & $\begin{array}{l}15.9 \pm 7.6 \\
15(0-34)\end{array}$ & $28(70.0 \%)$ & 37 (92.5\%) \\
\hline 4 & $8(44.4 \%)$ & $10(55.6 \%)$ & $\begin{array}{l}13.4 \pm 17.3 \\
10.5(1-79)\end{array}$ & $9(50.0 \%)$ & 5 (27.8\%) & $\begin{array}{l}11.3 \pm 4.6 \\
10(5-19)\end{array}$ & $9(50.0 \%)$ & $14(77.8 \%)$ \\
\hline $\begin{array}{l}p \\
\text { Location }\end{array}$ & 0.000 & 0.017 & $0.357^{c}$ & 0.628 & 0.046 & $0.002^{c}$ & 0.019 & 0.316 \\
\hline Proximal colon & 4 (I2.5\%) & 7 (21.9\%) & $\begin{array}{l}14.5 \pm 12.6 \\
9.5(3-53)\end{array}$ & I (3.I\%) & 17 (53.1\%) & $\begin{array}{l}18.8 \pm 11.2 \\
15(5-64)\end{array}$ & $26(81.3 \%)$ & 25 (78.1\%) \\
\hline Distal colon & 7 (I7.I\%) & II (26.8\%) & $\begin{array}{l}16.8 \pm 21.6 \\
10(1-122)\end{array}$ & $2 \mathrm{I}(5 \mathrm{I} .2 \%)$ & 20 (48.8\%) & $\begin{array}{l}15.9 \pm 7.7 \\
14(0-33)\end{array}$ & 29 (70.7\%) & $36(87.8 \%)$ \\
\hline Rectum & I (6.3\%) & $6(37.5 \%)$ & $\begin{array}{l}20.1 \pm 18.9 \\
12(1-64)\end{array}$ & 15 (93.8\%) & $10(62.5 \%)$ & $\begin{array}{l}12.4 \pm 5.4 \\
12.5(2-2 \mid)\end{array}$ & $10(62.5 \%)$ & I 5 (93.8\%) \\
\hline $\begin{array}{l}P \\
\text { Dukes }\end{array}$ & 0.550 & 0.516 & $0.714^{c}$ & 0.000 & 0.647 & $0.102^{c}$ & 0.348 & 0.295 \\
\hline B & $9(20.5 \%)$ & $17(38.6 \%)$ & $\begin{array}{l}17.9 \pm 17.2 \\
\mid I(1-79)\end{array}$ & $21(47.7 \%)$ & $18(40.9 \%)$ & $\begin{array}{l}14.2 \pm 7.6 \\
12.5(0-34)\end{array}$ & $26(59.1 \%)$ & 39 (88.6\%) \\
\hline C & $3(10.0 \%)$ & 4 (I3.3\%) & $\begin{array}{l}15.1 \pm 21.9 \\
10(1-122)\end{array}$ & II (36.7\%) & $20(66.7 \%)$ & $\begin{array}{l}20.9 \pm 10.4 \\
19(9-64)\end{array}$ & $28(93.3 \%)$ & $26(86.7 \%)$ \\
\hline$D$ & 0 & $3(20.0 \%)$ & $\begin{array}{l}15.5 \pm 13.4 \\
10(6-53)\end{array}$ & 5 (33.3\%) & $9(60.0 \%)$ & $\begin{array}{l}14.6 \pm 7.7 \\
12(5-33)\end{array}$ & II (73.3\%) & II (73.3\%) \\
\hline$p$ & 0.106 & 0.044 & 0.764 & 0.496 & 0.077 & $0.002^{c}$ & 0.005 & 0.340 \\
\hline Treatment & & & & & & & & \\
\hline $\begin{array}{l}\text { Immediate } \\
\text { resection }\end{array}$ & $12(15.4 \%)$ & $2 \mathrm{I}(26.9 \%)$ & $\begin{array}{l}15.9 \pm 18.5 \\
10(1-122)\end{array}$ & 27 (34.6\%) & 39 (50.0\%) & $\begin{array}{l}16.6 \pm 9.4 \\
15(0-64)\end{array}$ & 56 (7I.8\%) & $66(84.6 \%)$ \\
\hline DCS + resection & 0 & 3 (27.3\%) & $\begin{array}{l}21.3 \pm 16.3 \\
17(4-50)\end{array}$ & $10(90.9 \%)$ & 8 (72.7\%) & $\begin{array}{l}14.9 \pm 5.7 \\
14(8-27)\end{array}$ & 9 (81.8\%) & 10 (90.9\%) \\
\hline$p$ & 0.162 & 0.980 & $0.160^{\circ}$ & 0.000 & 0.157 & $0.70 \mathrm{I}^{\mathrm{c}}$ & 0.483 & 0.580 \\
\hline
\end{tabular}


Table 6 (Continued)

\begin{tabular}{|c|c|c|c|c|c|c|c|c|}
\hline & Mortality & Morbidity $^{\mathbf{a}}$ & $\mathbf{L O S}^{b}$ & Ostomy & $\begin{array}{l}\text { Complementary } \\
\text { treatment }\end{array}$ & LN analyzed & $\begin{array}{l}\text { LN } \\
\text { adequate } \\
\text { clearance }\end{array}$ & RO \\
\hline \multicolumn{9}{|l|}{ Approach } \\
\hline \multirow[t]{2}{*}{ Open } & 12 (I5.8\%) & $24(31.6 \%)$ & $18.0 \pm 19.3$ & 33 (43.4\%) & $8(61.5 \%)$ & $15.7 \pm 7.8$ & $53(69.7 \%)$ & $64(84.2 \%)$ \\
\hline & & & II (I-I22) & & & $14(0-34)$ & & \\
\hline \multirow[t]{2}{*}{ Laparoscopy } & 0 & 0 & $8.1 \pm 4.6$ & $4(30.8 \%)$ & $39(51.3 \%)$ & $20.0 \pm 13.9$ & $12(92.3 \%)$ & 12 (92.3\%) \\
\hline & & & $7(3-18)$ & & & $19(8-64)$ & & \\
\hline$\underline{p}$ & 0.123 & 0.018 & 0.009 & 0.392 & 0.495 & 0.265 & 0.090 & 0.445 \\
\hline \multicolumn{9}{|c|}{$\begin{array}{l}\text { Notes: aMorbidity represents the total number of patients who had at least I con } \\
\text { 'For patients with } 2 \text {-stage treatment, LOS is the sum of the } 2 \text { admissions. 'Diffe } \\
\text { variable is not normal. }{ }^{\mathrm{d}} \text { Comparison between } 2 \text { continuous variables or between } \\
\text { with a linear regression. When the } 2 \text { variables are somehow correlated, the co } \\
\text { p-values are reported in bold. } \\
\text { Abbreviations: ASA, American Society of Anesthesiologists; DCS, damage con } \\
\text { Table } 7 \text { Multivariate analysis on resected patients ( } 89 \text { cases) }\end{array}$} \\
\hline \multirow[t]{2}{*}{ Dependent variable } & & \multicolumn{3}{|c|}{ Independent } & \multirow{2}{*}{\multicolumn{2}{|c|}{ Correlation coefficient }} & & $p$-value \\
\hline & & \multicolumn{3}{|c|}{ prognostic factors } & & & & \\
\hline \multirow[t]{2}{*}{ Mortality } & & \multicolumn{2}{|l|}{ ASA } & \multicolumn{3}{|c|}{0.156} & & 0.000 \\
\hline & & \multicolumn{2}{|l|}{ Dukes } & \multicolumn{3}{|c|}{-0.115} & & \\
\hline \multirow[t]{3}{*}{ Morbidity } & & \multicolumn{2}{|l|}{ ASA } & \multicolumn{3}{|c|}{0.170} & & 0.000 \\
\hline & & \multicolumn{2}{|l|}{ Dukes } & \multicolumn{3}{|c|}{-0.136} & & \\
\hline & & \multicolumn{2}{|c|}{ Laparoscopic resection } & \multicolumn{3}{|c|}{-0.287} & & \\
\hline \multirow[t]{2}{*}{ LOS } & & \multicolumn{2}{|c|}{ Admission to treatment } & \multicolumn{3}{|c|}{0.997} & & 0.000 \\
\hline & & \multicolumn{2}{|c|}{ Onset to admission } & \multicolumn{3}{|c|}{0.068} & & \\
\hline \multicolumn{2}{|l|}{ Ostomy } & \multicolumn{2}{|c|}{ Distal cancer } & \multicolumn{3}{|c|}{0.458} & & 0.000 \\
\hline \multicolumn{2}{|l|}{ Chemoradiotherapy } & \multicolumn{2}{|l|}{ Age $>70$} & \multicolumn{3}{|c|}{-0.307} & & 0.004 \\
\hline \multirow[t]{2}{*}{ LN analyzed } & & ASA & & & -4.953 & & & 0.000 \\
\hline & & Distal ca & & & -3.164 & & & \\
\hline LN adequate clearance & & ASA & & & -0.197 & & & 0.000 \\
\hline & & Dukes & & & 0.140 & & & \\
\hline $\mathrm{R}+$ & & Laparosc & pic resection & & -0.231 & & & 0.000 \\
\hline & & Onset to & admission & & 0.001 & & & \\
\hline
\end{tabular}

Abbreviations: ASA, American Society of Anesthesiologists; LN, lymph nodes; LOS, length of stay.

the different set up of the emergency services; Italian ones traditionally always being consultant-delivered, with expert review and decisions available at any time. Furthermore, UK guidelines on the treatment of bowel cancer ${ }^{10}$ suggest that those cases should preferably be dealt with by a specialist colorectal surgeon, so patients with CRC presenting with a complication are sometimes just stabilized in emergency and transferred to a specialist colorectal surgeon as soon as possible. If the patient comes in during the weekend, it is possible that he or she would not receive any diseasedirected treatment until Monday morning. These differences can also explain why in the Italian group the vast majority of patients underwent resection within 24 hours from admission, whereas in the Manx group less than half had emergency resection. The delay of emergency treatment was significantly related to the total length of hospital stay and showed a trend toward increased morbidity, thus suggesting that the decision-making process should in all circumstances be as swift as possible.

Despite presenting early to hospital, Manx patients had, more frequently, a metastatic disease at admission. We are not sure if this is due to a random effect or to different biology and behavior of the tumor. The higher incidence of advanced cancer can explain, at least partially, the fact that many more patients in the Manx group had only palliative treatment, compared to those in the Italian group. However, it may also be due to the different attitude toward advanced and metastatic disease, where UK guidelines suggest only palliative treatment (considering chemotherapy if indicated), while Italian surgeons - in the absence of clearly restrictive guidelines - are inclined to take a more aggressive approach.

In our series, the choice of treatment was directly related to the kind of presentation and location of the tumor, staged treatment being more frequent in distal cancers. It is well 
known that right colon cancers more frequently present late in their course with respect to left colon cancers, and this can at least partially explain why palliative treatment was more frequent in right colon cancers.

It appears that patients with the highest probability of long-term survival were offered a more aggressive approach. In fact, younger patients ( $<70$ years old) and those with lower ASA scores were more often offered some form of chemoradiotherapy and had a better nodal clearance. A similar mechanism can explain, in our opinion, why Dukes B patients had higher morbidity than Dukes $\mathrm{C}$ and $\mathrm{D}$, a more aggressive - and hence more prone to complications - approach being applied in those with better chances.

As expected, mortality and morbidity were higher in elderly patients and in those with multiple comorbidities, thus suggesting a more prudent approach in these patients.

Comparison of the 2 branches of treatment did not show any significant difference, but patients in the immediate resection group had higher mortality, and showed a trend toward worse node clearance and a lower rate of negative margins with respect to delayed resection patients, thus confirming findings reported in the literature. ${ }^{9,23}$ Unfortunately, like most of the published articles on this topic, our study lacks a long-term follow-up which could be the definitive endpoint to establish the best treatment, so we decided to consider oncologic outcomes such as good nodal clearance and R0 resection as reliable surrogates, as they are known to positively affect survival. Slightly worse oncologic parameters in the group of immediate resections can potentially be associated with poor prognosis, but, even in the presence of this discrete trend, our data do not allow us to infer that immediate resection is associated with poor long-term survival. This issue has not been clarified yet. In fact, while there is good evidence clearly demonstrating that emergency presentation is independently associated with worse disease-free survival and local recurrence, ${ }^{6}$ some other authors showed that worse survival in patients operated on in emergency may not be due to the emergency operation itself, but to some other clinical factors, including a higher stage at presentation. ${ }^{26}$

Patients with 2-stage treatment were more likely to have a stoma. This apparent paradox can be easily explained by the fact that 2-stage treatment entails some form of DCS in emergency, and in our series this has almost always been a diversion ileostomy or colostomy. It is likely that a more extensive use of stents could reduce the odds of having a temporary stoma, but only if the concerns related to the use of stents as a bridge to surgery are fully resolved.$^{27}$ However, multivariate analysis showed that the odds of having a stoma are independently associated only to the distal location of the cancer; hence, the higher rate of stoma in staged treatment can also be due to the higher rate of distal cancers in the same treatment arm.

Patients who had a staged treatment had a higher possibility of receiving a laparoscopic resection, with all the advantages associated with a mini-invasive approach, and chemoradiotherapy. Furthermore, they also were likely to have the benefit of being operated on by subspecialist colorectal surgeons after formal discussion with a multidisciplinary team.

In our experience, laparoscopic resections are associated with lower mortality and morbidity, shorter hospital stay, better nodal clearance, and a higher rate of $\mathrm{R} 0$ resection with respect to immediate resection. In particular, laparoscopic resection is independently associated with low morbidity and R0 resection. Despite the progress and standardization of laparoscopic colorectal surgery in elective patients, most $(>80 \%)$ emergency resections are still performed by laparotomy. ${ }^{25}$ One of the reasons for the poor "enthusiasm" for the use of laparoscopy in emergency colorectal surgery can be the general perception that such an approach is more difficult and can be associated with worse results. ${ }^{28}$ We are well aware of the enormous practical difficulties faced when trying to implement a program of emergency resective bowel surgery off-hours and during weekends, but at least a couple of systematic reviews ${ }^{28,29}$ demonstrated that laparoscopic bowel resection in emergency is feasible and does not imply an increase in mortality and morbidity. The only remaining issue is the longer operative time, which in our opinion is not an insurmountable difficulty, considering the widely demonstrated advantages of mini-invasive surgery in cancer patients and in the acute setting.

This study obviously has the limitations of its retrospective design, and the 2 main groups having different sizes. However, the total number of patients recruited is quite significant and allows us to draw some interesting conclusions. Merging 2 groups from different social environments has not been perceived as a problem, but a good way to reduce selection bias.

\section{Conclusion}

Our study did not demonstrate a clear superiority of staged treatment over immediate resection, or vice versa, in patients with resectable CRC presenting as emergency, so both approaches can be considered safe and effective. However, 2 -stage treatment is associated with lower mortality and a higher rate of laparoscopic resection and adjuvant or 
neoadjuvant treatment, all positive determinants of a better outcome. For this reason, although we agree that the ultimate decision should stay with the on-call surgeon and his/her discussion with the patient, we feel that a staged treatment should always be considered as a viable option until new research, and possibly a proper randomized trial, provides new evidence.

\section{Author contribution}

All authors contributed toward data analysis, drafting and critically revising the paper and agree to be accountable for all aspects of the work.

\section{Disclosure}

The authors report no conflicts of interest in this work.

\section{References}

1. International Agency for Research on Cancer. Colorectal cancer. Estimated incidence, mortality and prevalence worldwide in 2012 Available from: http://globocan.iarc.fr/Pages/fact_sheets_cancer.aspx. Accessed July 8, 2017

2. Cancer Research UK. Bowel Cancer Statistics. Available from: http:// www.cancerresearchuk.org/health-professional/cancer-statistics/ statistics-by-cancer-type/bowel-cancer. Accessed July 8, 2017.

3. Associazione Italiana di Oncologia Medica, Associazione Italiana Registri Tumori. I Numeri del Cancro in Italia 2016. Roma, Italy: Il Pensiero Scientifico Editore; 2016. Available from: http://www. registri-tumori.it/PDF/AIOM2016/I_numeri_del_cancro_2016.pdf. Accessed July 8, 2017

4. Gunnarsson H, Jennische K, Forssell S, et al. Heterogeneity of colon cancer patients reported as emergencies. World J Surg. 2014;38(7):1819-1826.

5. Renzi C, Lyratzopoulos G, Card T, Chu TP, Macleod U, Rachet B. Do colorectal cancer patients diagnosed as an emergency differ from non-emergency patients in their consultation patterns and symptoms? A longitudinal data-linkage study in England. $\mathrm{Br} J$ Cancer. 2016;115(7):866-875.

6. Hogan J, Samaha G, Burke J, et al. Emergency presenting colon cancer is an independent predictor of adverse disease-free survival. Int Surg. 2015;100(1):77-86.

7. Amelung FJ, Consten ECJ, Siersema PD, Tanis PJ. A population-based analysis of three treatment modalities for malignant obstruction of the proximal colon: acute resection versus stent or stoma as a bridge to surgery. Ann Surg Oncol. 2016;23(11):3660-3668.

8. van Hooft JE, Bemelman WA, Oldenburg B, et al. Colonic stenting versus emergency surgery for acute left-sided malignant colonic obstruction: a multicentre randomised trial. Lancet Oncol. 2011;12(4):344-352.

9. Oistamo E, Hjern F, Blomqvist L, Falken Y, Pekkari K, AbrahamNordling M. Emergency management with resection versus proximal stoma or stent treatment and planned resection in malignant left-sided colon obstruction. World J Surg Oncol. 2016;14(1):232.

10. National Institute for Clinical Excellence. Improving Outcomes in Colorectal Cancers. Manual Update. London, UK: National Institute for Clinical Excellence; 2004. Available from: https://www.nice.org. uk/guidance/csg5/resources/improving-outcomes-in-colorectal-cancerupdate-pdf-773376301. Accessed July 2, 2017.
11. Becher D, Peitzman AB, Sperry JL, et al. Damage control operations in non-trauma patients: defining criteria for the staged rapid source control laparotomy in emergency general surgery. World J Emerg Surg. 2016;11:10.

12. Dindo D, Demartines N, Clavien PA. Classification of surgical complications. A new proposal with evaluation in a cohort of 6336 patients and results of a survey. Ann Surg. 2004;240(2):205-213.

13. Agha RA, Fowler AJ, Rajmohan S, Barai I, Orgill DP; PROCESS Group. Preferred reporting of case series in surgery; the PROCESS guidelines. Int J Surg. 2016;36(Pt A):319-323.

14. Tekkis PP, Kinsman R, Thompson MR, Stamatakis JD; Association of Coloproctology of Great Britain, Ireland. The Association of Coloproctology of Great Britain and Ireland study of large bowel obstruction caused by colorectal cancer. Ann Surg. 2004;240(1):76-81.

15. Morita S, Ikeda K, Komori T, et al. Outcomes in colorectal surgeondriven management of obstructing colorectal cancers. Dis Colon Rectum. 2016;59(11):1028-1033.

16. Association of ColoProctology of Great Britain and Ireland. Guidelines for the Management of Colorectal Cancer 2007. Available from: http://www.acpgbi.org.uk/content/uploads/2007-CC-ManagementGuidelines.pdf. Accessed July 8, 2017.

17. Arezzo A, Balague C, Targarona E, et al. Colonic stenting as a bridge to surgery versus emergency surgery for malignant colonic obstruction: results of a multicentre randomised controlled trial (ESCO trial). Surg Endosc. 2017;31(8):3297-3305.

18. Deans GT, Krukowski ZH, Irwin ST. Malignant obstruction of the left colon. Br J Surg. 1994;81(9):1270-1276.

19. Moran B, Cunningham C, Singh T, et al. Association of Coloproctology of Great Britain and Ireland (ACPGBI): guidelines for the management of cancer of the colon, rectum and anus (2017). Surgical management. Colorectal Dis. 2017;19(Suppl 1):18-36.

20. National Comprehensive Cancer Network. Colon Cancer. Available from: https://www.tri-kobe.org/nccn/guideline/colorectal/english/colon. pdf. Accessed July 8, 2017.

21. De Salvo GL, Gava C, Pucciarelli S, Lise M. Curative surgery for obstruction from primary left colorectal carcinoma: primary or staged resection? Cochrane Database Syst Rev. 2004;(2):CD002101.

22. Min CK, Kim HO, Lee D, et al. Obstructive left colon cancer should be managed by using a subtotal colectomy instead of colonic stenting. Ann Coloproctol. 2016;32(6):215-220.

23. Ogawa M, Watanabe M, Eto K, et al. Clinicopathological features of perforated colorectal cancer. Anticancer Res. 2009;29(5): 1681-1684.

24. Zielinski MD, Merchea A, Heller SF, You YN. Emergency management of perforated colon cancers: how aggressive should we be? J Gastrointest Surg. 2011;15(12):2232-2238.

25. NHS Digital. National Bowel Cancer Audit-Annual Report 2016. 2016. Available from: http://content.digital.nhs.uk/catalogue/PUB22797/naticlin-audi-bowe-canc-2016-rep-v2.pdf. Accessed July 7, 2017.

26. Weixler B, Warschkow R, Ramser M, et al. Urgent surgery after emergency presentation for colorectal cancer has no impact on overall and diseasefree survival: a propensity score analysis. BMC Cancer. 2016;16:208.

27. van Hooft JE, van Halsema EE, Vanbiervliet G, et al. Self-expandable metal stents for obstructing colonic and extracolonic cancer: European Society of Gastrointestinal Endoscopy (ESGE) Clinical Guideline. Endoscopy. 2014;46(11):990-1053.

28. Chand M, Siddiqui MR, Gupta A, et al. Systematic review of emergent laparoscopic colorectal surgery for benign and malignant disease. World J Gastroenterol. 2014;20(45):16956-16963.

29. Agresta F, Arezzo A, Allaix ME, Arolfo S, Anania G. Current status of laparoscopic colorectal surgery in the emergency setting. Updates Surg. 2016;68(1):47-52. 


\section{Publish your work in this journal}

Cancer Management and Research is an international, peer-reviewed open access journal focusing on cancer research and the optimal use of preventative and integrated treatment interventions to achieve improved outcomes, enhanced survival and quality of life for the cancer patient. The manuscript management system is completely online and includes a very quick and fair peer-review system, which is all easy to use. Visit http://www.dovepress.com/testimonials.php to read real quotes from published authors.

Submit your manuscript here: https://www.dovepress.com/cancer-management-and-research-journal 